\title{
Editorial \\ Advanced Technologies for the Optimization of Internal Combustion Engines
}

\author{
Cinzia Tornatore *(D) and Luca Marchitto
}

Institute of Science and Technology for Sustainable Energy and Mobility (STEMS-CNR), Italian National Rsearch Council, Via Marconi 4, 80125 Napoli, Italy; luca.marchitto@stems.cnr.it

* Correspondence: cinzia.tornatore@stems.cnr.it

Citation: Tornatore, C.; Marchitto, L. Advanced Technologies for the Optimization of Internal Combustion Engines. Appl. Sci. 2021, 11, 10842. https://doi.org/10.3390/ app112210842

Received: 10 November 2021 Accepted: 12 November 2021 Published: 17 November 2021

Publisher's Note: MDPI stays neutral with regard to jurisdictional claims in published maps and institutional affiliations.

Copyright: (C) 2021 by the authors. Licensee MDPI, Basel, Switzerland. This article is an open access article distributed under the terms and conditions of the Creative Commons Attribution (CC BY) license (https:/ / creativecommons.org/licenses/by/ $4.0 /)$.
Even in a scenario where electric vehicles gain market share and the sale of internal combustion engines is gradually reduced, at the present time, there are still no real options that can totally replace the internal combustion (IC) engine over the entire range of its applications. In the short-to-medium term, on-road and off-road transportation will most likely be characterized by a mix of solutions, including strongly electrified powertrain configurations, as well as conventional vehicles powered by IC engines.

The combustion engine will continue playing a central role; for this reason, there is a pressing need for its further optimization in terms of thermal efficiency and pollutant emissions. This goal can be achieved through more efficient and environmentfriendly technologies.

The aim of this Special Issue is to put together the recent research in advanced technologies for the optimization of internal combustion engines in order to help the scientific community address the efforts toward the development of higher-power engines with lower fuel consumption and pollutant emissions. This Special Issue contains 11 technical articles that have been peer-reviewed under the journal's rigorous review criteria.

Papers [1,2] deal with water injection technology that represents a promising solution to make turbocharged spark-ignition engines operate with higher compression ratios, higher boost pressures, and stoichiometric combustions at high loads. This allows a reduction in brake-specific fuel consumption and, thus, in $\mathrm{CO}_{2}$ emissions on the overall engine map. In [1], a detailed experimental analysis of a low-pressure water spray in the intake manifold (PWI technology) was presented, covering a lack of experimental data on automotive PWI systems. The obtained results evidenced how significant benefits in terms of atomization quality can be obtained by adopting injection pressure and water temperature levels compliant with standard low injection pressure technologies.

An alternative way of introducing water in an SI engine is in the form of an emulsion with gasoline (water-in-gasoline emulsions (WiGE)). This solution shows some advantages compared with the standard separate injections of water and gasoline. In [2], the authors performed an experimental investigation of WiGE effects on the performance and emissions of a turbocharged port fuel injection spark-ignition engine. WiGE was produced through a prototype micro-channel emulsifier that allows using a very small amount of surfactant to create stable emulsions. Water-in-gasoline emulsions demonstrated to be a suitable technique to reduce fuel consumption at medium/high loads of turbocharged sparkignition engines, enabling stoichiometric combustions while preserving the turbine blades from severe thermal stresses.

Two contributions to this Special Issue deal with the use of alternative fuels for internal combustion engines as a promising solution for a more sustainable operation. The research work reported in [3] assessed the combustion and performance of a dual-fuel operation in a spark-ignition engine that simultaneously integrates acetone-butanol-ethanol (ABE) and hydroxy $(\mathrm{HHO})$ doping in comparison with standalone gasoline operation. The implementation of the dual-fuel operation in spark-ignition engines proved to be a valuable tool 
for controlling emissions and reducing fuel consumption while maintaining combustion performance and thermal efficiency.

In [4], an experimental study was carried out on the effects of diesel surrogates (hydrotreated vegetable oil (HVO) and oxymethylene ethers $\left(\mathrm{OME}_{\mathrm{X}}\right)$ ) on main spray and combustion characteristics. The different physical-chemical properties of $\mathrm{HVO}$ and $\mathrm{OME}_{\mathrm{X}}$ make the study of their behavior in compression ignition engines essential. Quantitative parameters describing the evolution of diesel-like sprays such as liquid length, spray penetration, ignition delay, lift-off length, and flame penetration, as well as soot formation, were assessed in a constant high-pressure and high-temperature installation using optical diagnostics.

Combustion stability, engine efficiency, and emissions in a multi-cylinder sparkignition internal combustion engine can be improved through the advanced control and optimization of individual cylinder operation. In [5], experimental and numerical analyses were carried out on a twin-cylinder turbocharged port fuel injection spark-ignition engine to evaluate the influence of cylinder-by-cylinder variation on performance and pollutant emissions. The proposed numerical methodology represents a valuable tool to support engine design and calibration, with the aim to improve both performance and emissions.

With respect to the optimization of compression ignition engines, two contributions to the Special Issue [6,7] deal with the optimization of the injection process since fuel mixing is critical in determining combustion efficiency and emissions levels.

In [6], simulation optimization methods and methods based on evolutionary algorithms were elaborated on for the optimization of the design and technology of injector nozzles in terms of minimizing energy losses on friction in compression ignition engines. The technical state of the injector apparatus significantly affected the engine performance, fuel consumption, toxicity, and smoke opacity of outlet gases. Alternatively, in [7], an analysis was carried out on the effects of the fuel injection rate shape on the diesel spray mixing process using a numerical simulation. The results show that a changing injection rate shape can enhance mixing during injection and achieve better mixing after the end of injection.

In [8], an investigation was carried out to improve energy conversion for a fourstroke free-piston engine. Unlike crankshaft-based engines, free-piston engines allow for a higher degree of freedom in shaping the piston trajectory, including adaptive compression ratios, which enables optimal operation with alternative fuels. The possibility of adapting the stroke course results in new degrees of freedom with which the combustion process can be optimized. In this work, four-stroke trajectories with different amplitudes and piston dynamics were proposed and analyzed regarding efficiency. The trajectories were described analytically so that they can be used for a prototype in future work.

Paper [9] deals with the use of a pre-turbine small-sized oxidation catalyst. The earlier activation of catalytic converters in internal combustion engines is becoming highly challenging due to the reduction in exhaust gas temperature caused by the application of $\mathrm{CO}_{2}$ reduction technologies. In this context, the use of pre-turbine catalysts arises as a potential way to increase the conversion efficiency of the exhaust aftertreatment system. In this work, a small-sized oxidation catalyst consisting of a honeycomb thin-wall metallic substrate was placed upstream of the turbine to benefit from the higher temperature and pressure before the turbine expansion. The effects of this device on engine performance and emissions under driving conditions were shown.

The last two papers published in this Special Issue $[10,11]$ refer to the use of numerical methods to aid the engine development process.

In [10], a computationally efficient tabulated chemistry solver for internal combustion engine optimization using stochastic reactor models was developed. The use of chemical kinetic mechanisms in computer-aided engineering tools for internal combustion engine simulations is of high importance for studying and predicting pollutant formation of conventional and alternative fuels. However, the usage of complex reaction schemes is accompanied by high computational costs in $0 \mathrm{D}, 1 \mathrm{D}$, and 3D computational fluid dynamics 
frameworks. This work aimed to address this challenge and allow broader deployment of detailed chemistry-based simulations, such as in multi-objective engine optimization campaigns. A fast-running tabulated chemistry solver coupled to a $0 \mathrm{D}$ probability density function-based approach was proposed for the modeling of compression and spark-ignition engine combustion.

Finally, in [11], the authors introduced and validated a new transient simulation methodology of an ICE coupled to a hybrid architecture vehicle to predict internal combustion engine performance and emissions in real driving conditions. A one-dimensional computational fluid dynamic software was used and suitably coupled to a vehicle dynamics model. The results show that a crank angle resolution approach to the vehicle simulation is a viable and accurate strategy to predict engine emissions during any driving cycle with a computation effort compatible with the tight schedule of a design process.

Acknowledgments: Editors would like to acknowledge all the authors of the submitted papers for choosing this Special Issue and the peer reviewers for their dedication. Editors would also like to acknowledge the Section Managing Editor, Melon Zhang, for his precious support.

Conflicts of Interest: The authors declare no conflict of interest.

\section{References}

1. Postrioti, L.; Brizi, G.; Finori, G.M. Experimental Analysis of Water Pressure and Temperature Influence on Atomization and Evolution of a Port Water Injection Spray. Appl. Sci. 2021, 11, 5980. [CrossRef]

2. Tornatore, C.; Marchitto, L.; Teodosio, L.; Massoli, P.; Bellettre, J. Performance and Emissions of a Spark Ignition Engine Fueled with Water-in-Gasoline Emulsion Produced through Micro-Channels Emulsification. Appl. Sci. 2021, 11, 9453. [CrossRef]

3. Guillin-Estrada, W.; Maestre-Cambronel, D.; Bula-Silvera, A.; Gonzalez-Quiroga, A.; Duarte-Forero, J. Combustion and Performance Evaluation of a Spark Ignition Engine Operating with Acetone-Butanol-Ethanol and Hydroxy. Appl. Sci. 2021, 11, 5282. [CrossRef]

4. Pastor, J.V.; García-Oliver, J.M.; Micó, C.; García-Carrero, A.A.; Gómez, A. Experimental Study of the Effect of Hydrotreated Vegetable Oil and Oxymethylene Ethers on Main Spray and Combustion Characteristics under Engine Combustion Network Spray A Conditions. Appl. Sci. 2020, 10, 5460. [CrossRef]

5. Teodosio, L.; Marchitto, L.; Tornatore, C.; Bozza, F.; Valentino, G. Effect of Cylinder-by-Cylinder Variation on Performance and Gaseous Emissions of a PFI Spark Ignition Engine: Experimental and 1D Numerical Study. Appl. Sci. 2021, 11, 6035. [CrossRef]

6. Monieta, J.; Kasyk, L. Optimization of Design and Technology of Injector Nozzles in Terms of Minimizing Energy Losses on Friction in Compression Ignition Engines. Appl. Sci. 2021, 11, 7341. [CrossRef]

7. Naruemon, I.; Liu, L.; Liu, D.; Ma, X.; Nishida, K. An Analysis on the Effects of the Fuel Injection Rate Shape of the Diesel Spray Mixing Process Using a Numerical Simulation. Appl. Sci. 2020, 10, 4983. [CrossRef]

8. Tempelhagen, R.; Gerlach, A.; Benecke, S.; Klepatz, K.; Leidhold, R.; Rottengruber, H. Investigations for a Trajectory Variation to Improve the Energy Conversion for a Four-Stroke Free-Piston Engine. Appl. Sci. 2021, 11, 5981. [CrossRef]

9. Serrano, J.R.; Piqueras, P.; De la Morena, J.; Ruiz, M.J. Influence of Pre-Turbine Small-Sized Oxidation Catalyst on Engine Performance and Emissions under Driving Conditions. Appl. Sci. 2020, 10, 7714. [CrossRef]

10. Matrisciano, A.; Franken, T.; Gonzales Mestre, L.C.; Borg, A.; Mauss, F. Development of a Computationally Efficient Tabulated Chemistry Solver for Internal Combustion Engine Optimization Using Stochastic Reactor Models. Appl. Sci. 2020, 10, 8979. [CrossRef]

11. Marinoni, A.; Tamborski, M.; Cerri, T.; Montenegro, G.; D’Errico, G.; Onorati, A.; Piatti, E.; Pisoni, E.E. 0D/1D Thermo-Fluid Dynamic Modeling Tools for the Simulation of Driving Cycles and the Optimization of IC Engine Performances and Emissions. Appl. Sci. 2021, 11, 8125. [CrossRef] 